\title{
A curva de Rangel: origem, desenvolvimento e a formalização de Bresser-Pereira e Nakano
}

\author{
OSMANI PONTES MORENO \\ ANDRÉ DE MELO MODENESI*
}

The Rangel curve: Origin, development and formalization of Bresser-Pereira and Nakano.

For Rangel inflation is caused by oligopolies and is necessary because it prevents a depression in an economy with low propensity to consume. Facing inflation, government prints money to avoid a liquidity crisis. This conception implies a double opposition to monetarist thought: conceives inflation as functional phenomenon and reverses the causality established by the quantitative equation. Bresser and $\mathrm{Na}$ kano were highly influenced by Rangel and stress that inflation is caused by oligopolies and also propose a "sanctioning role" of the state. However, these authors go further Rangel arguing that in recession inflation accelerates thus, formalizing a negative relationship between GDP growth and inflation, according with the so called "Rangel curve".

Keywords: Rangel curve; inflation; oligopolies; Brazil.

JEL Classificação: B5; B59; E5; E3.

\section{INTRODUÇÃO}

No complexo contexto histórico do início dos anos 1980 - marcado por profunda recessão e aceleração da inflação - destaca-se o desenvolvimento de três concepções da teoria da inflação inercial, desenvolvida, quase que simultaneamente,

\footnotetext{
* Respectivamente, Economista e pesquisador do Grupo de Estudos sobre Moeda e Sistema Financeiro do Instituto de Economia da Universidade Federal do Rio de Janeiro (IE/UFRJ).E-mail: osmanipmoreno@ gmail.com. Professor do IE/UFRJ e Pesquisador do CNPq. E-mail: amodenesi@gmail.com. Os autores agradecem a contribuição de Rui L. Modenesi e os comentários de Luiz C. Bresser-Pereira, Ricardo Bielschowsky, Patrick Fontaine e Marcelo T. Miterhof, isentando-os de quaisquer responsabilidades sobre eventuais erros e omissões. Este trabalho se baseia na Monografia de Graduação de O. Moreno. Os autores também agradecem os comentários de Carlos Pinkusfeld e de Franklin Serrano, membros da banca examinadora.
} 
em distintos centros acadêmicos do país: PUC-RJ, Unicamp e FGV-SP. Diante da conturbada conjuntura da chamada década perdida, a diferenciação entre essas teorias não foi alvo de um debate acadêmico mais profundo ${ }^{1}$. A visão da PUC-RJ, em larga medida, acabou prevalecendo, e popularizando-se - notadamente por ter originado os planos Cruzado e Real.

Uma análise mais detalhada dos trabalhos de Bresser e Nakano, professores da FGV-SP, permite a identificação de relações de contribuição recíprocas entre a teoria desses autores e a teoria de inflação desenvolvida por Ignácio Rangel, advogado maranhense dedicado ao estudo de economia. Por um lado, as ideias de Bresser e Nakano foram bastante influenciadas pela concepção de Rangel (1963). Por outro, Bresser e Nakano acabaram por explicitar (e formalizar) uma das mais inovadoras e originais contribuições de Rangel (1963): uma relação contrária àquela prevista pela curva de Phillips. Somente depois dos trabalhos de Bresser (1981) e de Bresser e Nakano (1984a e 1984b), Rangel (1985b) enunciou de forma mais clara aquilo que ficou conhecido como a "curva de Rangel", mesmo assim sem definir explicita e formalmente uma relação (positiva) de causalidade entre recessão e inflação. Contemporaneamente, a curva de Rangel continuou sendo desenvolvida por Bresser e Rego (2013), que acrescentaram à análise pioneira de Rangel o papel crucial do setor externo na dinâmica subjacente à relação positiva entre recessão e inflação.

É importante analisar essas inter-relações entre as obras dos autores citados, visto que a própria contribuição de Rangel é pouco difundida entre os economistas, notadamente os mais jovens. Esse fato - somado ao tumultuado contexto histórico dos anos 1980 - dificultou a identificação das contribuições mútuas entre as concepções de Rangel e a de Bresser-Nakano aqui exploradas. Isso não compromete, de forma alguma, a relevância da contribuição de Rangel. Ele propôs uma nova concepção sobre a inflação, ao contemplar de forma muito criativa as peculiaridades da dinâmica da economia brasileira.

A filiação teórica de Rangel é controversa. Muitos autores interpretam sua obra como uma aplicação particular da teoria estruturalista ao caso brasileiro. No entanto, há importantes afastamentos entre a teoria de Rangel e o estruturalismo. Castro (2012), por exemplo, considera que Rangel não tratou apenas de um fato histórico isolado e específico, tendo desenvolvido uma verdadeira teoria, geral e aplicável a diferentes casos, além do brasileiro. Em suas palavras:

[m] esmo referenciada em um momento histórico e, obviamente, tratando de alguns de seus aspectos característicos, a obra [de Rangel] transcende seu caráter de ocasião. É, de fato, uma teoria, não só pela forma rigorosa de sua formulação, como também por seu elevado grau de universalidade. (Castro, 2012, p. 30)

\footnotetext{
${ }^{1}$ Serrano (1986) aponta que o suposto consenso em torno da teoria da inflação inercial era muito mais aparente e superficial do que, à primeira vista, se poderia supor. Não se pretende aprofundar esse debate nem mesmo detalhar a contribuição específica de cada um desses centros no desenvolvimento dessa teoria. A esse respeito ver, por exemplo, Bresser-Pereira (2010) e Serrano (2010).
} 
No ano em que se completam cem anos do nascimento e vinte da morte de Ignácio Rangel, este trabalho objetiva estabelecer tais relações de contribuição mediante a apresentação de temas comuns tratados por Rangel e Bresser-Nakano em suas principais obras. São quatro seções além desta introdução. Na primeira seção é apresentada a teoria de inflação de Ignácio Rangel destacando-se três aspectos: as necessidades, as causas e as consequências da inflação. Essa seção também destacará duas importantes oposições entre o pensamento de Rangel e a visão monetarista: o estabelecimento de uma funcionalidade para a inflação e a inversão da relação de causalidade - entre (oferta de) moeda e nível geral de preços - proposta pela teoria quantitativa da moeda (TQM). Na segunda seção são tratadas as concepções de Bresser-Nakano a respeito de temas semelhantes aos tratados por Rangel, a saber, a endogeneidade da moeda e o papel dos oligopólios no processo inflacionário. A terceira seção destaca a relação inversa da curva de Phillips: uma relação direta entre recessão e inflação, destacando-se a formalização da curva de Rangel feita por Bresser e Nakano. Por fim, a quarta seção conclui o trabalho, comentando as principais contribuições de cada autor para o desenvolvimento da curva de Rangel.

\section{A CONCEPÇÃO DA INFLAÇÃO DE IGNÁCIO RANGEL: NECESSIDADES, CAUSAS E CONSEQUÊNCIAS}

Rangel formula uma análise de inflação sui generis, identificando causas e consequências inteiramente distintas daquelas previstas tanto pela teoria ortodoxa - monetarista e (velho) keynesiana -, quanto pela heterodoxia estruturalista da Comissão Econômica para América Latina (CEPAL). Também é inovadora a sua explicitação sobre o caráter necessário ou funcional da inflação brasileira: sua principal função é prevenir um processo depressivo na economia.

Ousadia, independência intelectual e originalidade são os traços mais distintivos da obra de Rangel (1963), que desenvolve uma análise absolutamente peculiar da inflação. A inflação brasileira foi publicada durante o período de transição entre dois modelos teóricos que foram fortemente dominantes, tanto na academia quanto entre os gestores de política econômica: a sintese neoclássica - que tinha na curva de Phillips sua pedra fundamental ${ }^{2}$; e ii) o monetarismo de Milton Friedman (1956, 1968), que considerava que "a inflação é sempre e em qualquer lugar um

\footnotetext{
${ }^{2}$ No início dos anos 1950, formou-se um consenso - contrário à crença quanto à estabilidade do equilíbrio macroeconômico - , dentre a vasta maioria dos economistas e policymakers, denominado síntese neoclássica (Samuelson, 1955). Os principais autores da síntese (conhecidos como velhos-keynesianos) foram: Hicks (Laureado com o Prêmio Nobel em 1972), Tobin (Laureado com o Prêmio Nobel em 1981), Samuelson (Laureado com o Prêmio Nobel em 1970), e Klein (Laureado com o Prêmio Nobel em 1980). Houve um esforço de mediação entre os dois polos das duas principais escolas de pensamento macroeconômico à época: a clássica e a keynesiana. A crença na eficiência dos mecanismos de mercado no restabelecimento do pleno emprego foi substituída — fundamentalmente pela postulação da existência de rigidez no salário nominal - pelo reconhecimento da necessidade do gerenciamento da demanda agregada (notadamente pela gestão discricionária da política fiscal). Assim, a síntese neoclássica
} 
fenômeno monetário" (Friedman, 1989, p. 32, itálicos no original). Como visto adiante, a concepção de Rangel do processo inflacionário contraria, frontalmente, tanto a curva de Phillips quanto a visão monetarista da inflação. Assim, a curva de Rangel opõe-se, simultaneamente, aos dois modelos teóricos hegemônicos que vigoraram tanto nas décadas anteriores quanto posteriores à sua publicação.

A percepção aguçada das singularidades da economia brasileira também marcou a obra de Rangel, que figura entre os mais percucientes pensadores brasileiros. A esse respeito, Bielschowsky $(1988$, p. 248) ressalta que: “[...] sua grande obsessão passou a ser o entendimento dessa realidade [brasileira] através de análises que recusavam o uso de teorias importadas sem a devida adaptação às condições históricas específicas do país". De fato, Rangel foi um dos poucos economistas capazes de evitar uma prática historicamente recorrente no âmbito das ciências sociais brasileiras, e denunciada, com propriedade, por Alberto Torres (1914): a importação de teorias desenvolvidas nos países centrais e a sua mera transposição acrítica para as sociedades e economias periféricas - i.e., sem a devida observância das peculiaridades a estas inerentes ${ }^{3}$.

Fazendo uso tanto da teoria macroeconômica quanto da microeconômica e, também, da economia política, Rangel mobiliza K. Marx e J. M. Keynes para criticar a curva de Phillips, a TQM e o estruturalismo da CEPAL. Sua teoria da inflação será analisada em três partes: i) necessidade (ou funcionalidade) da inflação; ii) causas da inflação e iii) consequências de um impulso inflacionário.

No que se refere à necessidade ou funcionalidade da inflação, o ponto de partida de Rangel é a questão agrária:

[o] Brasil empreendeu sua industrialização sem previamente remodelar as relações de produção na agricultura. Daí resulta que, acima das contradições internas do seu setor capitalista (entre o capital e o trabalho) e do seu setor feudal (entre o latifúndio feudal e a servidão de gleba), paire a contradição entre o seu lado moderno [...] e o seu lado arcaico [...] (Rangel, 1963, p. 36, itálicos no original).

Ele destaca que o processo de desenvolvimento do sistema capitalista no Brasil instaurou-se sem uma reforma agrária que permitisse eliminar os elementos arcaicos e modernizar a estrutura fundiária. Esse fato comprometeu o desenvolvimento adequado do próprio capitalismo ${ }^{4}$. De modo geral, o desenvolvimento ca-

caminhava pari passu com a convicção acerca da existência de um trade-off estável entre inflação e desemprego - conforme a curva de Phillips (1958) original e a versão de Samuelson e Solow (1960).

3 “A nossa curiosidade intelectual e o nosso interesse por assimilar produções e estudos alheios [...] devem conduzir-nos a dilatar o círculo das nossas colheitas de saber, substituindo a atitude passiva, que nos tem trazido a receber as ideais que nos exporta o acaso, ou o instinto político de outros povos por um trabalho autônomo de escolha e de seleção consciente. [...] Na prática, cada povo tem a sua filosofia, a sua ciência, a sua arte, a sua política [...]” (Torres, 1914, p. 29).

${ }^{4}$ Essa ideia volta a ser reafirmada cerca de vinte anos depois em Rangel (1983a e 1990). Rangel (1990) 
pitalista exige um aumento na produtividade do trabalho rural, a fim de gerar um excedente agrícola - para abastecer as cidades de alimentos - e um excedente de mão de obra, para garantir uma oferta de trabalho para a indústria nascente. Porém, diante do atraso da estrutura agrária brasileira, o aumento da produtividade foi maior do que o necessário, gerando excedentes em demasia e ocasionando uma "crise agrária" 5 . O excedente de mão de obra não foi totalmente absorvido pela indústria, gerando desemprego que, por sua vez, reduziu os salários e o poder de barganha dos trabalhadores.

A consequência desse processo é o aumento da taxa de exploração do trabalho, expressa pela relação entre mais-valia $(P)$ e salários $(V)$, como destaca Rangel $(1963$, p. 39): "Em síntese, o capitalismo brasileiro desenvolve-se nas condições de um 'exército industrial de reserva' exorbitante, cujo efeito é elevar a taxa de exploração do sistema $\left(\frac{P}{V}\right)$ ". Além disso, Rangel considera a razão investimento/consumo $\left(\frac{I}{C}\right)$ uma forma de expressar a taxa de exploração: "Basta, por enquanto, determinar que a razão $\left(\frac{I}{C}\right)[\ldots]$ não passa de uma reencarnação $[\ldots]$ da razão $\left(\frac{P}{V}\right)[\ldots]$ ”. Uma vez que a propensão a consumir da economia pode ser representada pela razão $\left(\frac{C}{I}\right)$, percebe-se que, quanto maior a taxa de exploração do trabalho, menor a propensão a consumir da economia.

Como observa Rangel (1963, p. 61), quanto maior a desigualdade da distribuição de renda, menor a parcela da renda voltada para a demanda global e, portanto, maior a parcela da renda voltada para os investimentos. É com base nisso que Rangel (1963, p. 35) conclui: “[...] a verdade é que o Brasil é um país de baixíssima propensão a consumir [...]”, ou seja, há na economia brasileira uma insuficiência de demanda. Tal fato se agrava com o crescente aumento da produtividade agrícola, não acompanhado por um aumento dos salários. Assim, há uma tendência à redução da propensão a consumir na economia.

Rangel sugere que a economia possui alguns mecanismos de defesa diante dessa baixa tendência a consumir, dentre eles os direitos trabalhistas, os sindicatos e o "empreguismo" por parte do governo. No entanto, tais mecanismos são ineficazes. Com isso, o sistema passa a depender fortemente das imobilizações ${ }^{6}$ para compensar o baixo consumo no curto prazo $^{7}$. No entanto, em uma economia com

destaca ainda a importância da inflação para a industrialização brasileira desde os anos 1930 até os 1980 .

${ }^{5}$ Nesse sentido, a crise agrária pode ser entendida como um desequilíbrio atrelado ao processo de desenvolvimento, o que aproxima Rangel da análise estruturalista. No entanto, em Rangel esse desequilíbrio causa problemas na demanda e não tem efeitos inflacionários, ao contrário da concepção estruturalista que vê consequências sobre a oferta com efeitos inflacionários.

${ }^{6}$ Ao longo de a toda sua obra, Rangel considera imobilizações todos os tipos de "aprazamento de consumo", incluindo-se nessa expressão investimentos de produção (compra de bens de produção) e de consumo (compra de bens de consumo duráveis). Segundo o autor, isso permite distinguir consumo corrente de consumo futuro.

${ }^{7}$ Nesse aspecto, Rangel (1963, pp. 105-109) faz uma análise marxista aprofundando a questão. No longo prazo, a taxa de exploração do trabalho é $\left(\frac{P}{V}\right)$. No curto prazo, movimentos conjunturais 
baixa propensão a consumir e tendência à ociosidade da capacidade produtiva (que aumenta com a expansão dos investimentos), a rentabilidade do capital tende a ser negativa, desestimulando-se as imobilizações. Porém, devido ao atraso econômico do país, ainda há setores que possuem capacidade produtiva insuficiente que acabam recebendo parcela dos investimentos. Quando tais setores também ficam saturados (ou com excesso de capacidade), é necessária a introdução de novas atividades; mas até que isso ocorra, surge uma tendência à queda da taxa de imobilização. Cria-se, então, uma tendência à depressão na economia.

Assim, em uma situação em que a inflação se torna "regular" e "institucionalizada" (Rangel, 1963, p. 33), os agentes incorporam a elevação de preços em suas expectativas definindo, a partir daí, a parcela da renda mantida sob a forma de moeda (determinada pela preferência pela liquidez, em clara referência a Keynes) e a parcela da renda que será gasta. O resultado da inflação é a perda de valor da moeda, levando a um enfraquecimento da preferência pela liquidez: “A inflação é necessária porque provoca uma 'corrida aos bens materiais' [...] porque 'deprime a preferência pela liquidez do sistema'” (Rangel, 1963, p. 67, negritos nossos).

Diante da inflação, os agentes buscam se proteger da perda de valor da moeda e demandam outra reserva de valor mais "segura" que a moeda — que, a princípio, pode ser qualquer bem. Com a queda da preferência pela liquidez, os agentes (consumidores e firmas) gastam, mesmo sem uma necessidade real. Do ponto de vista das firmas, isso significa que as empresas investem independentemente do nível de utilização de capacidade instalada - i.e., mesmo com capacidade ociosa. Logo, a inflação estimula as imobilizações aumentando, assim, a demanda agregada compensando a insuficiência de demanda efetiva, que é própria da economia brasileira. Nesse ponto, Rangel distancia-se, radicalmente, tanto dos estruturalistas quanto dos monetaristas:

\section{[...] tanto estruturalistas como monetaristas [...] colocam como centro de sua problemática uma hipotética insuficiência da oferta, perante uma demanda supostamente excessiva, quando a verdade é que o nível de demanda é este que aí temos [...] precisamente por causa da inflação. (Rangel, 1963, p. 31, itálicos no original e negritos nossos)}

\footnotetext{
determinam a taxa de exploração conjuntural $\left(\frac{P}{V}\right)$. Um aumento na taxa conjuntural via aumentos de mais-valia e de salários, mesmo com a primeira subindo mais (aumentando a taxa estrutural no longo prazo), gera ganhos absolutos para os trabalhadores, e é isso que eles desejam, o que seria bom para patrões e trabalhadores. Tal situação só ocorre se os empresários aumentarem o uso da capacidade produtiva empregando mão de obra. Se investirem somente no aumento da capacidade produtiva, tal aumento será maior do que o aumento da renda, pois o multiplicador é pequeno (tem relação direta com a propensão a consumir, que é pequena); logo, o aumento da ociosidade será ainda maior no longo prazo, além disso, nessa situação os trabalhadores perdem. Outra possibilidade é o aumento da maisvalia diante da redução dos salários, o que seria não um aumento da renda, mas uma redistribuição desta em favor dos empresários.
} 
Assim, a inflação não é causada por um problema de oferta diante de uma demanda excessiva - como pensavam os estruturalistas. Antes pelo contrário, a inflação eleva a demanda agregada evitando uma depressão. Ao explicar os motivos que levam a sociedade a permitir a subida dos preços, Rangel relaciona, diretamente, a taxa de inflação com o crescimento econômico. Em outras palavras, a inflação permite o crescimento a partir de um cenário de recessão:

[...] a economia precisa de que os preços subam. Esta subida de preços, continuada e, por assim dizer, institucionalizada, deve ter uma função estratégica, relacionada com o nível e com a taxa de expansão do produto real [...] (Rangel, 1963, p. 30, itálicos no original e negritos nossos)

No entanto, Rangel (1963, p. 70) faz um alerta de que a continuidade desse processo levará a aumentos cada vez maiores da capacidade ociosa e, consequentemente, a quedas na rentabilidade do capital. Isso, por sua vez, exigirá uma inflação cada vez maior para gerar imobilizações que compensem a falta de demanda. Tal situação pode levar à depressão ou à inflação galopante.

Além disso, a inflação também é funcional por contribuir para o fortalecimento do sistema financeiro. Ao deprimir o valor da moeda, cria-se oferta de recursos monetários ociosos e também demanda por capitais de investimento. A este respeito, Bielschowsky (1988, p. 280) ressaltou que: “[...] além de amortecer a crise, a inflação estaria, não obstante a conjuntura recessiva, viabilizando o crescimento do sistema financeiro interno, indispensável, na interpretação do autor à retomada do crescimento [econômico]".

Em suma, para Rangel, a inflação tem uma funcionalidade explícita. Ao enxergar a alta dos preços como não sendo, necessariamente, prejudicial ao funcionamento do sistema econômico, Rangel contrapõe-se radicalmente à tradição monetarista (clássica e de Friedman).

Por outro lado, sua concepção aproxima-se, de certa forma, da ideia de inevitabilidade da inflação, que caracteriza a tradição estruturalista. De uma forma geral, para estes autores a inflação era resultado de distorções geradas pelo crescimento econômico. Consequentemente, o controle de preços passaria, obrigatoriamente, por uma interrupção do crescimento. Nesse sentido, a inflação seria, em última instância, uma consequência inevitável do processo de desenvolvimento. Neste aspecto, Rangel diferencia-se dos estruturalistas ao propor que a inflação evita uma tendência à depressão, assumindo, assim, uma funcionalidade propriamente dita.

Por exemplo, Furtado (1959) identificava na inflação um mecanismo de transferência de renda para setores que, posteriormente, usariam esses recursos para

\footnotetext{
${ }^{8}$ Repare que se trata de uma das mais distintivas marcas da teoria monetária ortodoxa. É uma visão que tem sido historicamente dominante: a inflação é considerada, necessariamente, prejudicial ao sistema econômico pelas escolas clássica, monetarista, novo-clássica, novo-keynesiana e, mais contemporaneamente, pelos teóricos do Novo Consenso Macroeconômico.
} 
realizar investimentos. Assim, ele considerava não apenas os efeitos monetários como, também, os efeitos reais da inflação opondo-se, assim, aos monetaristas: “[...] essa expansão [da renda monetária] é apenas o meio pelo qual o sistema procura redistribuir a renda real com o fim de alcançar uma nova posição de equilíbrio" (Furtado, 1959, p. 238). Outros autores filiados à CEPAL, como Noyola (1956), Sunkel (1958), Pinto (1961) e Seers (1962), também identificavam certa funcionalidade na inflação.

De forma geral, embora com diferenças entre si, os estruturalistas consideravam que o crescimento econômico dos países latino-americanos gerava, necessariamente, desequilíbrios na estrutura produtiva. Esses desequilíbrios, por sua vez, estão na origem da inflação. Sendo assim, a inflação está umbilicalmente ligada ao crescimento. Dessa maneira, a "correção das distorções causadoras de inflação" seria obtida à custa de uma desaceleração do crescimento econômico, em linha com o trade-off entre inflação e desemprego proposto pela curva de Phillips. Essa questão fica clara em Bielschowsky (1988, p. 28):

[t]ais desproporções [na estrutura produtiva] resultam em inflação, o que introduz o dilema político da escolha entre uma situação de crescimento rápido mas desequilibrado e uma situação de relativa estagnação em que as forças do crescimento são obstruídas pelas deficiências estruturais do sistema econômico. (Bielschowsky, 1988, p. 28)

Sendo assim, uma concepção, próxima — porém distinta — à de funcionalidade da inflação já estava presente em alguns autores estruturalistas latino-americanos (ainda que com diferenças entre eles). É importante notar que identificar um caráter "funcional" da inflação não significa justificá-la ou promovê-la: esses autores formularam propostas de eliminação das falhas estruturais causadoras de inflação, apenas discordando de combatê-la sacrificando-se o crescimento econômico.

Em relação às causas da inflação, é interessante notar que, na visão de Rangel, embora a inflação seja necessária para evitar a depressão da economia, ela não é causada diretamente por nenhum setor econômico de maneira intencional. Na realidade, a função da sociedade é apenas permitir que as causas da inflação se desenvolvam e que ela seja endossada pelo governo, como será visto mais à frente.

Para Rangel, o aumento dos preços tem início na comercialização do setor agrícola. A comercialização desses bens tem relação oligopsônica com a oferta, que é (fortemente) elástica, permitindo que os intermediários manipulem tanto a quantidade ofertada quanto os preços (ao produtor). Além disso, a comercialização agrícola tem relação oligopolista com a demanda — que é (altamente) inelástica permitindo, assim, que os intermediários manipulem os preços finais (aos consumidores). O resultado é evidentemente um elevado poder dos intermediários em fixar os preços finais dos produtos agrícolas. Nas palavras de Rangel (1963, p. 90):

[...] manipulando os preços ao produtor e submetendo este último a condições erráticas de comercialização, o oligopsônio-oligopólio deprime 
e desorganiza continuamente a produção, tornando-a escassa; apoiado nessa escassez [...] aproveita-se da inelasticidade da demanda, a qual deixa indefeso o público consumidor, para impor a este preços extorsivos [...]. (Rangel, 1963, p. 90, itálicos no original e negritos nossos)

No raciocínio de Rangel, tais grupos formadores de preços são "pré-capitalistas", não resultando de nenhuma "ordem técnica"; assim, deveriam ser "desmantelados". Contudo, o que ocorre é que o governo não apenas permite a operação como incentiva tais grupos. O incentivo ocorre por intermédio de uma "máquina" estatal que facilita a reunião dos componentes desse grupo a fim de reduzir possíveis concorrências entre eles. O que se forma, então, é um monopsônio-monopólio que possui ainda mais poder de manipular preços, tanto do lado da oferta quanto do lado da demanda agrícola.

Quanto às consequências da inflação, o impulso inflacionário, após surgir no setor agrícola (como descrito anteriormente), tende a se alastrar pelo restante do sistema econômico. Rangel utiliza a fórmula $(M V=P T)^{9}$ para mostrar como ocorrem os movimentos de preços na economia e, em seguida, criticar (e inverter) a relação de causalidade entre moeda e preços, prevista pela TQM clássica ${ }^{10}$.

No seu entender, um aumento inicial dos preços agrícolas (de $P$ para $P^{\prime}$ ) é representado como uma elevação setorial de preços tal que $M V<P^{\prime} T$. Como observa Rangel (1963, p. 29), o aumento de preços de "[...] itens tão decisivos da cesta de consumo das massas trabalhadoras [...] implica redução do salário real [...]”. A consequência disso é a queda da demanda dos trabalhadores. No entanto, a demanda de alimentos, por ser inelástica, não se reduz, cabendo esta redução aos bens de demanda mais elástica. Como bem observa Rangel (1963, p. 29), a perda real "modifica a estrutura da demanda popular", levando a: um aumento da parcela da renda gasta com alimentos; e a uma redução da parcela da renda gasta com os demais bens. O efeito disso é a retenção de estoques $(t)$ por parte das empresas dos setores de demanda mais elástica. Assim, a igualdade da equação de trocas é restabelecida: $M V=P^{\prime}(T-t)$.

Repare que, para os monetaristas, basta que a autoridade monetária mantenha $M$ constante para forçar uma queda de preços, restaurando-se, assim, a igualdade da equação de trocas. Para Rangel, o reequilíbrio se dá pela retenção de estoques nos setores de demanda mais elástica. Há, assim, uma assimetria setorial na dinâmica inflacionária: "[...] a elevação original dos preços e a retenção dos estoques têm lugar em áreas diferentes do sistema econômico.” (Rangel, 1963, p. 30, itálicos no original).

\footnotetext{
${ }^{9} \mathrm{Na}$ equação de trocas da TQM, $M$ é a oferta monetária, determinada pelo Banco Central; $V$ é a velocidade de circulação da moeda, ou, como define Rangel, a "eficácia da moeda"; $P$ é o nível geral de preços, obtido como uma ponderação dos preços da economia; e $T$ é a quantidade física de bens produzidos.

${ }^{10}$ A concepção monetarista da inflação - e a neutralidade da moeda — é outro traço distintivo da teoria monetária ortodoxa, também encontrando respaldo nas escolas clássica, monetarista, novo-clássica, novo-keynesiana e no Novo Consenso Macroeconômico.
} 
Com tal retenção de estoques, segundo Rangel (1963, p. 86): "rompe-se o equilíbrio econômico-financeiro das empresas", pois os estoques aumentam em prejuízo do disponível das firmas. Ou seja, as empresas perdem liquidez e recorrem ao sistema bancário - que concede empréstimos, contra as garantias dadas pelos estoques acumulados.

Os bancos eventualmente passam a enfrentar problemas de liquidez, levando o governo a emitir moeda para salvar o sistema bancário. Assim, o estoque monetário sobe para $M^{\prime}$, causando novo desequilíbrio (um aumento do lado esquerdo) na equação de trocas: $M^{\prime} V>P^{\prime}(T-t)$. Ao se desfazerem dos seus estoques as empresas (ainda que não intencionalmente) acabam por promover o restabelecimento da igualdade. Para isso é necessário recuperar o salário real dos trabalhadores, aumentando os salários nominais. Assim, tem-se que $M^{\prime} V=P^{\prime} T$.

Resumindo, a expansão monetária ocorre, pois o governo é obrigado a emitir moeda para evitar uma quebra do sistema bancário (e das empresas). Além disso, ele acaba por se beneficiar da inflação de duas formas: i) auferindo receita tributária, decorrente da venda dos bens que estavam estocados; e ii) ganhos sobre a moeda criada e devido aos depósitos compulsórios.

Destaca-se aqui uma oposição radical à tradição monetarista: a inversão da causalidade entre moeda e preços prevista pela TQM. Para Rangel, a emissão ocorre devido ao aumento dos preços e, não, ao contrário, como suposto pelos monetaristas: "[...] a emissão não é o ponto de partida da inflação, mas o seu ponto de chegada, isto é, sua culminação.” (Rangel, 1963, p. 25, negritos nossos). Isto significa que a inflação de fato surge no "bojo" da economia e não devido a decisões monetárias do governo. O governo tem um papel "passivo" nesse processo sendo vítima de uma "armadilha" da sociedade. Mais ainda, a emissão em si não gera nenhum efeito real além da reabsorção dos estoques, os efeitos reais são causados pelos próprios aumentos de preços (1963, p. 32). A emissão apenas evita que a inflação seja sufocada.

Em outras palavras, há uma causação reversa: a expansão monetária resulta do aumento dos preços ${ }^{11}$. Nesse sentido, Rangel encontra-se entre os precursores da teoria da moeda endógena, aproximando-se do chamado horizontalismo de Weintraub (1978), Kaldor (1982), Moore (1988) e Davidson (1977), dentre outros autores pós-keynesianos ${ }^{12}$.

Por fim, deve-se destacar, ainda, outra motivação do governo em permitir o

\footnotetext{
${ }^{11}$ Não se pretende traçar um histórico dessa concepção, cujas origens são remotas. Por exemplo, Thornton (1802), Fullarton (1845), Mill (1848) e Tooke (1856) chegaram a abordar, de forma tênue, o tema. Alguns consideram que Wicksell (1898) tenha sido o primeiro a considerar a inversão da causalidade da correlação (positiva) entre moeda e preços. Uma análise, menos profunda que a de Rangel, foi esboçada por Noyola (1957), ao considerar a expansão do crédito como um dos mecanismos de propagação da inflação. Mais recentemente, os teóricos da escola de ciclos reais de negócios defendem a causação reversa.

${ }^{12}$ Para mais detalhes, ver, por exemplo, o debate entre Carvalho (1993) e Costa (1993) e, também, Carvalho (2013).
} 
alastramento da alta dos preços: a necessidade de se manter as expectativas inflacionárias dos agentes, para deprimir a preferência pela liquidez e, portanto, estimular o consumo de bens materiais - sustentando, em última instância, a demanda agregada. Notadamente durante as fases depressivas do ciclo econômico, a inflação estimula as imobilizações. Vale notar que para Rangel o governo não tinha consciência desse mecanismo: o sistema econômico percebia de alguma forma que a "inflação era boa". O resultado é existência de uma cumplicidade, de certa forma velada, de todos os agentes econômicos, com a inflação.

\section{A CONCEPÇÃO DE BRESSER-PEREIRA E DE NAKANO A RESPEITO DE DOIS ELEMENTOS FUNDAMENTAIS: \\ A ENDOGENEIDADE DA MOEDA E O PAPEL DOS OLIGOPÓLIOS}

A concepção de inflação desenvolvida por Bresser-Pereira e Nakano é ampla, envolvendo diversos aspectos. Neste trabalho, serão tratados apenas dois temas que se relacionam especificamente com a obra de Rangel (1963): a endogeneidade da moeda e o papel dos oligopólios no processo inflacionário. O primeiro insere-se em um conjunto de críticas elaboradas por Bresser e Nakano, direcionadas principalmente à visão monetarista da inflação. Tais críticas constituem um arcabouço que resulta no abandono, por parte desses autores, dos modelos convencionais de inflação e serve de ponto de partida para a elaboração da referida concepção de inflação. O segundo tema se insere na análise feita por Bresser e Nakano dos papéis assumidos pelos diferentes agentes na nova fase do sistema capitalista, o capitalismo oligopolista.

Bresser e Nakano reafirmam a endogeneidade da moeda, contrapondo-se à concepção monetarista - de exogeneidade da moeda - , criticada por Bresser (1981):

[o]s velhos textos de economia definiam inflação como o aumento desproporcionado dos meios de pagamento em relação à renda nacional [...] O aumento dos preços era a consequência da inflação e não a própria inflação. Não se discutia se o aumento da quantidade de moeda causava ou não aumento generalizado de preços. Este ponto era pacífico. A discussão estava na determinação das causas do aumento da moeda em circulação. (Bresser-Pereira, 1981, p. 7)

Mais adiante conclui:

[o]ra, hoje não faz o menor sentido definir inflação nesses termos. Inflação é simplesmente o aumento generalizado e persistente de preços. É o processo de perda do poder aquisitivo da moeda. O aumento da quantidade de moeda poderá ser uma das causas da inflação, jamais a própria inflação. (Bresser-Pereira, 1981, p. 7, negritos nossos) 
Para Nakano (1982, p. 160): “[...] nada está mais longe da realidade do que a tradicional teoria neoclássica de preços”. Bresser (1981) e Bresser e Nakano (1984a, 1984b) concentram suas críticas a três elementos essenciais do monetarismo (ou da teoria neoclássica, de uma forma mais ampla): i) a oferta de moeda é exógena ao sistema econômico; ii) a causalidade se dá da moeda para preços; e iii) a moeda é neutra, não exercendo efeitos duradouros sobre variáveis reais.

As duas primeiras hipóteses podem ser criticadas por meio de um mesmo raciocínio. Um aumento do nível de preços que preceda um aumento da oferta de moeda, com a velocidade de circulação constante e o produto em equilíbrio, exigirá necessariamente um aumento da oferta de moeda para garantir a igualdade da equação de trocas. Em termos práticos, e em uma análise bem próxima à concepção de Rangel (1963), um aumento de preços reduz a quantidade real de moeda, ameaçando uma crise de liquidez. A solução é a autoridade monetária (ou o sistema bancário, via crédito) aumentar a oferta de moeda. Sendo assim:

[n] este caso, o aumento na quantidade de moeda não pode ser considerado causa ou fator acelerador de inflação, mas mero fator sancionador dessa inflação. A expansão monetária simplesmente acompanha a elevação dos preços, transformando-se em uma variável endógena do sistema, e não em uma variável exógena como pretende um tipo de pensamento linear como o monetarista. (Bresser-Pereira \& Nakano, 1984a, p. 13, negritos nossos)

O Estado assume um papel sancionador da inflação sempre que emite moeda a fim de evitar uma crise de liquidez. Assim, os autores aceitam a causação reversa defendida por Rangel: "[a] correlação entre o aumento da quantidade de moeda e taxa de inflação é indiscutível, mas a direção da relação causal é inversa daquela pretendida pelos monetaristas" (Bresser-Pereira \& Nakano, 1984a, p. 14).

A terceira hipótese neoclássica é criticada por Bresser e Nakano (1984b) devido à existência, no mundo real, de entesouramento. Como a moeda desempenha a função de reserva de valor, ela pode ser retida pelos agentes, como originalmente proposto por Keynes. Assim, haverá uma contração da demanda agregada e/ou do nível de produto. Logo, não há uma relação estável no longo prazo entre demanda por moeda e renda real.

Dentre os papéis atribuídos aos agentes econômicos, destaca-se o papel dado aos oligopólios. Para Bresser e Nakano, no capitalismo oligopolista, a grande empresa pode se valer de seu poder de mercado para administrar seu preço, independentemente do nível de atividade econômica. Isto é um exemplo do predomínio da inflação administrada sobre os demais tipos de inflação.

Bresser (1981), Nakano (1982) e Bresser e Nakano (1984a) consideram que, para qualquer nível de inflação, as empresas de um setor oligopolista podem ampliar suas margens de lucro, aumentando seus preços acima da inflação. Diante das fortes relações intersetoriais e das defasagens temporais dos reajustes, os demais agentes tentarão, ao menos, manter suas participações, em termos reais, na renda 
nacional (deteriorada pela inflação setorial). Utilizando mecanismos de indexação, também aumentam seus preços mais do que a inflação vigente, instaurando-se o conflito distributivo. Assim, a inflação setorial se alastra por toda a economia, entrando em ação os fatores aceleradores da inflaçã $O^{13}$.

É importante destacar que as empresas oligopolistas podem aumentar suas margens de lucro visando aumentar suas participações reais, na renda nacional ou, mesmo, visando manter sua participação, diante de uma queda nas vendas, em um cenário de recessão:

[p]ara manter a taxa de lucro (lucro sobre o capital), as empresas do setor oligopolista tenderão a aumentar suas margens de lucro nos períodos de recessão. Dessa forma, a queda nas vendas é compensada pelo aumento da margem, buscando manter-se o volume de lucro e a taxa de lucro. (Bresser-Pereira \& Nakano, 1984a, p. 9, negritos nossos)

Em suma, Bresser e Nakano (1984a) consideram que, em economias oligopolizadas, diante de uma recessão, a tendência natural das empresas é aumentar suas margens de lucro, assim gerando inflação. Tal ideia já se encontrava em Bresser (1981):

[i]maginemos que a economia entre em recessão, ou seja, entre na fase descendente do ciclo. Neste momento as empresas se verão diante de vendas declinantes. Para manter sua taxa de lucro [...] a alternativa óbvia será elevar a margem de lucro [...] Isto significará necessariamente o aumento de preços, considerando constante, para efeitos desta análise, a taxa de produtividade. (Bresser-Pereira, 1981, p. 16, negritos nossos)

Bresser e Nakano (1986) reafirmam que a inflação surge como um mecanismo de defesa das margens de lucro por parte das empresas oligopolistas: "O aumento das margens de lucro é um mecanismo de defesa das empresas para proteger a taxa de lucro ante a recessão, ou seja, à redução das vendas e ao correspondente aumento dos custos fixos unitários" (Bresser-Pereira \& Nakano, 1986, p. 72, negritos nossos). Esta análise permite concluir que há uma relação direta entre recessão e

\footnotetext{
${ }^{13}$ Caso a indexação seja plena (com coeficiente de realimentação igual a 1) e em sincronia temporal, após determinado período de tempo, o aumento inicial terá sido totalmente neutralizado, a estrutura de preços relativos retornará ao nível inicial e o aumento da inflação será igual ao aumento da inflação setorial original. Nesse caso, o agente que iniciou o aumento do preço pode iniciar nova elevação de preços, que será seguida pelos demais agentes, provocando outra rodada de aceleração inflacionária. Caso a indexação não seja plena e nenhum outro agente aumente seu preço, o nível de inflação deixa de acelerar-se. Além disso, para os autores, as empresas também desempenharão um papel mantenedor da inflação, caso apenas mantenham suas margens de lucro — objetivando manter sua participação real na renda nacional. Nesse caso, tal ação não acelera a inflação, apenas mantendo-a no mesmo patamar. Como ficará claro mais à frente, este último comportamento é o mais comum e confere um caráter inercial à inflação, ao passo que os fatores aceleradores se darão, sobretudo, devido a problemas ligados a crises do balanço de pagamentos.
} 
inflação, com causalidade da primeira para a segunda $a^{14}$. Este ponto é fundamental e será tratado na seção seguinte ${ }^{15}$.

\section{A FORMALIZAÇÃO DA CURVA DE RANGEL POR BRESSER E NAKANO}

Não se questiona a originalidade de Rangel (1963) no desenvolvimento daquilo que duas décadas depois foi chamado por Bresser e Nakano de "curva de Rangel”. De acordo com Bresser (1981):

[n]o Brasil, depois da análise clássica de Ignácio Rangel [...] verificou-se que essa correlação [da curva de Phillips] também não existia, ou melhor, que no período 1960-1980 revelou-se invertida. [...] Dezessete anos transcorreram do trabalho pioneiro de Rangel e a história só confirmou sua análise fundamental. (Bresser-Pereira, 1981, p. 4)

Rangel (1963) considera que a inflação resulta da ação de oligopólios-oligopsônios na comercialização de determinados bens agrícolas. Por outro lado, ele vê a inflação como uma forma de aumentar a demanda agregada, provocando retomada do crescimento, a partir de um cenário de recessão. Contudo, Rangel (1963) não afirma que a atuação dos oligopólios em recessão é mais agressiva (no sentido de aumentar seus preços) do que em períodos "normais" ou de crescimento. Sendo assim, é como se os oligopólios atuassem sempre aumentando margens, independentemente da fase do ciclo econômico. Fica a ideia de que a inflação surge como uma salvação para a recessão, resultando de um comportamento corriqueiro dos oligopólios.

Nesse sentido, a relação entre recessão e inflação não é formalizada por Rangel (1963). Essa explicitação só veio a ocorrer posteriormente. Rangel (1985b) constata empiricamente ${ }^{16}$, e explicita aquilo que ficou conhecido como a "curva de Rangel":

[...] há pelo menos um quartel de século, a inflação integra a síndrome da recessão, isto é, surge ou se exacerba quando a economia se desaquece e, inversamente, desaparece ou, pelo menos, tem sua intensidade reduzida,

\footnotetext{
${ }^{14}$ Para Nakano (1982), setores competitivos reduzem os preços diante de recessões. Assim, o efeito de uma recessão sobre o nível de preços depende da estrutura do sistema econômico: “[...] o que ocorrerá com a inflação acaba dependendo do peso relativo destes dois segmentos competitivos e oligopolizados na economia. Se o peso relativo dos setores concentrados for muito grande a recessão tende a realimentar a inflação compensando as quedas verificadas nos setores competitivos" (Nakano, 1982, p. 163). Contudo, como será visto na próxima seção, a conclusão geral dos autores é que a tendência é um aumento dos preços diante da recessão — em face do caráter oligopolista da economia brasileira.

${ }^{15}$ Na próxima seção será apresentada a análise de Bresser e Rego (2013), que torna mais claro o papel dos fatores aceleradores e mantenedores da inflação — sobretudo em períodos de recessão - e, também, explicita a relação desses fatores com a curva de Rangel.

${ }^{16}$ Rangel (1985b) utiliza dados de 1958 a 1983 da economia brasileira para construir uma curva para a atividade industrial e outra para a inflação, mostrando que existia uma relação inversa entre ambas.
} 
quando a economia se reaquece. Não há, portanto, nenhum trade-off a fazer, porque o combate a inflação é inseparável do combate à recessão [...] (Rangel, 1985b, p. 5, itálicos no original e negritos nossos)

Mais adiante, após comentar a regularidade entre inflação e recessão observada no Brasil, ele afirma:

[i]sso deve bastar para que nos apliquemos à busca de outra etiologia para o fenômeno da inflação, dado que a tradicionalmente aceita é incompatível com o fato óbvio de que a inflação se exacerba nos períodos recessivos, isto é, quando a demanda é mínima, vale dizer, quando a economia está sobrecarregada de desemprego e capacidade ociosa. (Rangel, 1985b, p. 13, itálicos no original)

Logo, por mais sutis que possam parecer as diferenças entre os dois trabalhos de Rangel, é somente em 1985 que ele apresenta sua concepção de forma clara e explícita, postulando a existência de uma relação direta entre recessão e inflação. Esse fato é percebido por Bresser e Rego (1993): “[...] Rangel, em 1985, formula de forma precisa uma ideia que já vinha desenvolvendo há muito: a 'curva de Rangel'. Rangel nega a teoria universalmente aceita, embutida na curva de Phillips [...]” (Bresser-Pereira; Rego, 1993, p. 114, negritos nossos).

Bresser (2010) também vê a explicitação da "curva de Rangel" apenas em 1985: "A curva de Rangel, já está presente em A inflação brasileira (1963), mas ela só foi exposta plenamente em 'Recessão, inflação e dívida externa' (1985)" (Bresser-Pereira, 2010, nota de rodapé n. 6, itálicos no original).

A ideia de haver uma relação direta entre recessão e inflação foi apresentada de forma mais clara e formalizada por Bresser e Nakano em trabalhos anteriores à Rangel (1985b). Isso foi feito, sobretudo, em Bresser (1981), Bresser e Nakano (1984a) e em Bresser e Nakano (1984b). Nesses artigos, a causalidade da relação é colocada de forma mais explícita. De fato, a ideia de uma inversão da curva de Phillips já estava presente em Bresser (1981):

[...] a correlação óbvia entre prosperidade, fase ascendente e auge do ciclo econômico com inflação, e entre fase declinante do ciclo ou recessão com deflação deixava de prevalecer. Agora passávamos a ter inflação em todas as fases do ciclo e a inflação podia inclusive acelerar-se nos períodos recessivos. (Bresser-Pereira, 1981, p. 4, negritos nossos)

Bresser e Nakano (1984b) mostram que, a partir de uma curva de Phillips tradicional, podem ocorrer rompimentos de duas hipóteses básicas do modelo tradicional, o que faz com que surja uma nova relação entre inflação e desemprego.

Os autores partem de uma curva de Phillips tradicional, que relaciona (negativamente) inflação e desemprego. Até determinado nível de desemprego $\left(d_{1}\right.$, no Gráfico 1), aumentos do desemprego implicam redução de preços (provavelmente porque as empresas ainda estão mantendo suas margens, enquanto os salários 
nominais estão caindo). Mas a partir desse ponto, as empresas passam a aumentar as margens de lucro diante da queda de vendas (provavelmente em magnitude maior que a queda dos salários nominais); e, portanto, aumentos de desemprego aumentam a inflação. A curva de preços (curva positivamente inclinada no gráfico 1) desprende-se da curva de salários e ocorre um primeiro rompimento da Phillips tradicional: o da relação salários nominais $x$ preços.

\section{Gráfico 1: Rompimento da relação salários nominais $x$ preços}

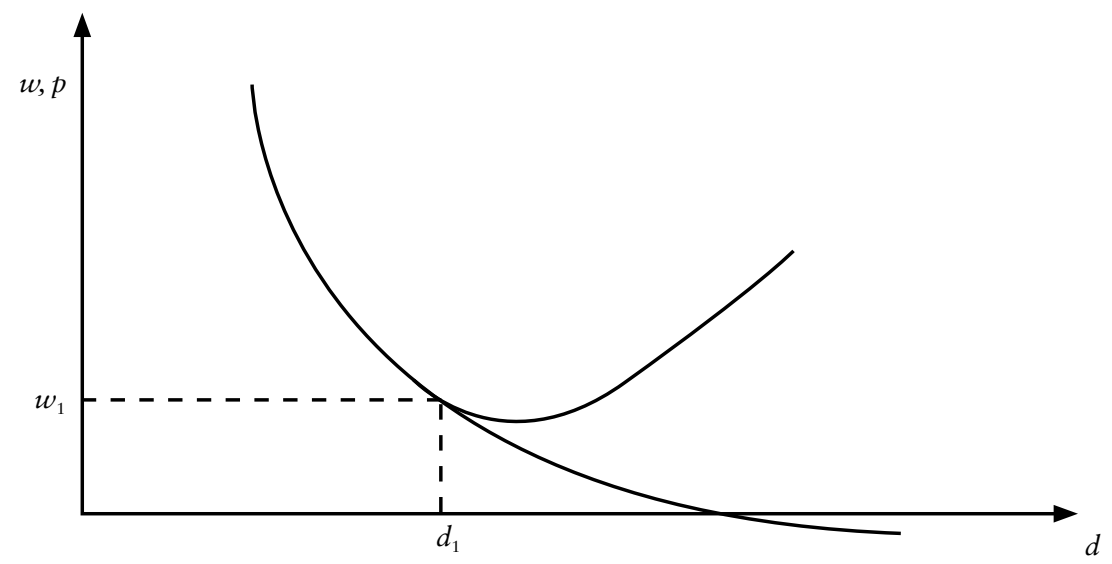

Fonte: Adaptado de Bresser e Nakano (1984b, p. 108)

Em resposta a esse aumento de preços, e mantido o poder de barganha dos trabalhadores, os sindicatos demandam aumentos salariais nominais. Assim, os salários nominais passam a aumentar, em todos os níveis, para cada aumento de desemprego. Dessa forma, a curva de Phillips vai se deslocando para cima (e para direita), como se a curva de salários tentasse acompanhar a curva de preços. Nesse momento dá-se o segundo rompimento da curva de Phillips: o da relação desemprego $x$ salário nominal.

A partir daí, a cada aumento de desemprego, a economia se desloca para pontos em diferentes curvas de Phillips (cada vez mais altas), e não mais ao longo da Phillips inicial. Surge, assim, uma nova relação em que aumentos do desemprego são acompanhados por elevações da inflação ${ }^{17}$.

Bresser e Nakano (1986), formalizam a dinâmica descrita acima no Gráfico 2. Os aumentos do desemprego (a partir de $d_{1}$ e até $d_{4}$ ) levam a economia a mover-se ao longo da curva definida pelos pontos $A-B-C-D$, indicando aumentos sucessivos na inflação.

\footnotetext{
${ }^{17}$ Bresser (1981) destaca que a curva de Phillips original deixou de se adequar à realidade econômica contemporânea: “Os dados de Phillips referem-se a um período anterior, dizem respeito à 'velha inflação', mostrando exatamente o inverso da estagflação” (Bresser-Pereira, 1981, p. 11).
} 


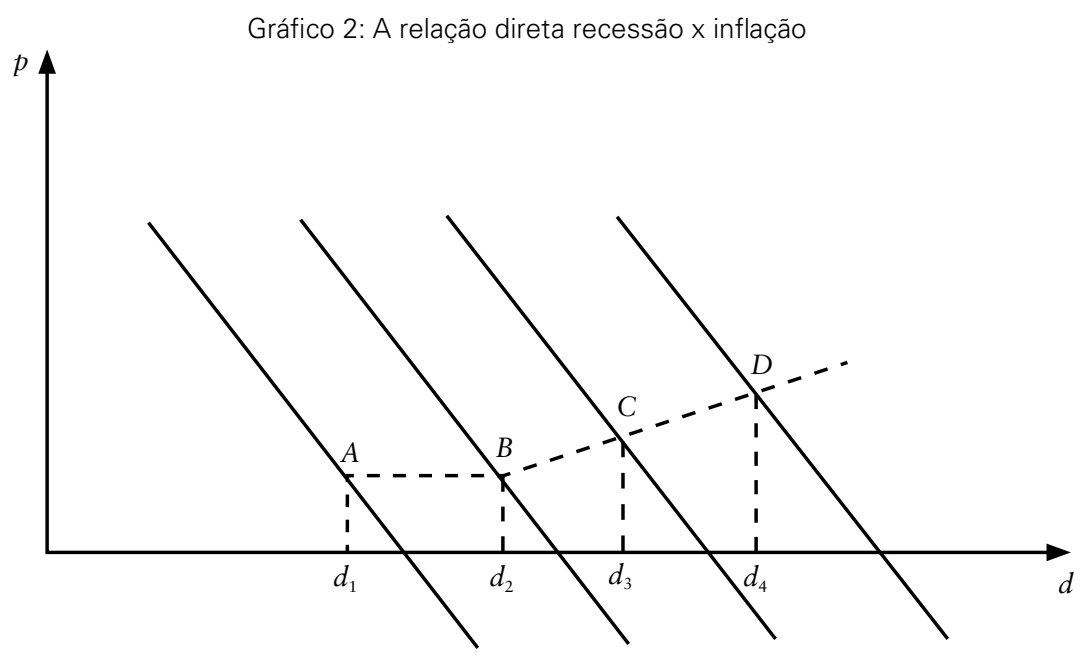

Fonte: Adaptado de Bresser e Nakano (1986, p. 73).

Assim, a proposição de uma relação direta (ou positiva) entre recessão e inflação foi desenvolvida por Bresser e Nakano, entre os anos de 1981 e 1984. Nesse sentido, eles contribuíram para Rangel explicitar sua curva, em 1985. Isso fica claro nas seguintes passagens de Rangel (1985a), em que primeiro afirma:

[e]ssa depressão brasileira [referindo-se a dados de 1980-1983] confirmou a tendência que já se vinha observando, havia pelo menos um quartel de século, isto é, simetricamente com a recessão, a inflação se elevava. Com a mesma regularidade com que declinava, quando a economia entrava em recuperação. Uma simetria perfeita, elegante, mesmo. (Rangel, 1985a, p. 432)

Em seguida, ao explicar a relação, reconhece que não tinha "respostas claras" e concorda com Bresser e Nakano (esboçando, finalmente, uma relação de causalidade):

[p]ara isso [relação direta entre inflação e recessão] não temos ainda respostas tão claras e contundentes, mas, pelo menos como primeira hipótese de trabalho, podemos alinhar dois fatos relevantes [em que, aqui, interessa apenas o primeiro]: a) como vem insistindo L. C. Bresser-Pereira, a economia acha-se fortemente oligopolizada, o que permite uma medida considerável de administração dos preços. O oligopólio, como se sabe, é um monopólio em potencial, desde que os oligopólios se entendam entre si [...] (Rangel, 1985a, p. 432)

A complementação que Bresser e Nakano deram (ao destacar a atuação dos oligopólios em recessões), nos anos 1980, à teoria seminal de Rangel (1963), explica parte da curva de Rangel (1985a). No entanto, ainda existiam algumas lacunas, 
a saber: i) na prática, nem sempre as empresas oligopolistas conseguem acelerar a inflação em períodos recessivos; e ii) a curva, especificada nesses termos, sugere um "caminho de volta" (que Rangel reconhece haver, ao passo que Bresser e Nakano não são muito enfáticos a esse respeito), pelo qual uma retomada do crescimento desaceleraria a inflação. Esse caminho de volta não está bem fundamentado nos trabalhos de Bresser e de Nakano, tampouco na obra de Rangel.

Recentemente, Bresser e Rego (2013) explicitam a possibilidade de movimentos (nos dois sentidos) ao longo da curva de Rangel. Os autores desenvolveram uma análise que se propõe a preencher as lacunas supracitadas. Tal análise passa pela diferenciação de fatores aceleradores e mantenedores da inflação. Em períodos de recessão, o mais provável é que os oligopólios mantenham suas margens, aumentando seus preços proporcionalmente à inflação. Esta ação, ao contribuir para manter a inflação naquele patamar, se configura como fator mantenedor da inflação. Esta é a essência da inflação inercial ${ }^{18}$ em Bresser e Nakano: os agentes aumentam seus preços na proporção em que a inflação aumenta - preservando, assim, suas participações na renda; e mantendo os preços relativos em equilíbrio. Em um momento posterior, todos os agentes passam a indexar seus preços criando-se uma inercialização plena da inflação.

Além disso, segundo Bresser e Rego (2013), nos países em desenvolvimento os períodos de recessão, muitas vezes, estão associados a crises financeiras no balanço de pagamentos. Estas, em geral, acabam resultando em desvalorização cambial que, por sua vez, acelera a inflação (dada a relevância do repasse cambial): "Hoje está claro que nas crises financeiras de balanço de pagamentos a taxa de câmbio se deprecia violentamente e, em consequência, a taxa de inflação aumenta" (Bresser-Pereira \& Rego, 2013, p. 17). Ainda de acordo com os autores, em momentos de crescimento econômico, o câmbio tende a se (sobre)valorizar e, portanto, a inflação se desacelera. Vale lembrar que, embora não assinalada nesses termos por Rangel, essa ideia é coerente com seu pensamento a respeito do comportamento da economia doméstica, em relação à economia internacional, como fica claro na sua análise sobre a dualidade do sistema econômico brasileiro ${ }^{19}$.

Assim, chegou-se a uma formulação mais abrangente da curva de Rangel. Uma recessão gera dois efeitos sobre o nível de preços: os fatores mantenedores (por meio da ação de oligopólios, que irão manter suas margens) e os fatores acelera-

\footnotetext{
${ }^{18}$ Essa ideia da inflação inercial era em parte rejeitada por Rangel, como mostra Castro (2012). Rangel (1987a) enxerga apenas o comportamento cíclico da inflação no contexto de uma recessão. Assim, considerava um exagero a ênfase dada por alguns economistas ao caráter inercial da inflação. Para ele, a ideia de inflação inercial considerava que a estabilização de preços dependia somente da transformação do "desejo de estabilização" em "força material”, sendo, portanto, uma ideia frágil. Crítica semelhante é encontrada em Rangel (1988b). Para mais detalhes ver Rangel (1983b, 1985c, 1986, 1987b, 1988a, 1988c, 1988d, 1989). No entanto, a ideia de inflação inercial não é totalmente incompatível com o pensamento de Rangel, afinal essa manutenção inflacionária resulta (ao menos em parte) diretamente da ação defensiva por parte de oligopólios.
}

19 Cf. Rangel (1957, 1962, 1981). 
dores (a desvalorização cambial, em momentos de crise no balanço de pagamentos), que deixam de agir em caso de retomada do crescimento econômico.

Essa concepção - mais completa e generalizada - da curva de Rangel contempla explicitamente a possibilidade de movimentos ao longo da curva de Rangel nos dois sentidos: i) a recessão acelera a inflação; ao passo que, ii) a expansão econômica desacelera a inflação. Segundo os autores: "Por isso temos a curva de Rangel: quando a crise se agrava, a inflação se acelera; quando a economia volta a crescer, a inflação desacelera" (Bresser-Pereira \& Rego, 2013, p. 17).

Bresser e Rego ressalvam, todavia, que a curva de Rangel constitui instrumento próprio para a análise da inflação como fenômeno de longo prazo, não se destinando, pois, a explicar acelerações inflacionárias no curto prazo, decorrentes de desequilíbrios entre oferta e demanda agregada.

\section{CONCLUSÃO}

O desenvolvimento da curva de Rangel foi apresentado como um processo contínuo, em que se destacam três momentos paradigmáticos, sumariados a seguir:

1. A contribuição original de Rangel (1963). Trata-se de uma formulação fundadora, em que os elementos fundamentais foram originalmente identificados (ainda que, algumas vezes, de forma não muito clara e explícita). Em primeiro lugar, Rangel situa a origem do fenômeno inflacionário no âmbito do processo econômico - mais especificamente, na dinâmica do ciclo de longo prazo da economia brasileira. Ele considera a inflação como sendo necessária ao funcionamento do sistema econômico. Ao enxergar funcionalidade na inflação, Rangel opõe-se frontalmente ao monetarismo. Em segundo lugar, Rangel introduz fundamentos microeconômicos na explicação da inflação. Este ponto merece destaque, pois confere atualidade à sua obra. A baixa aderência da inflação brasileira ao ciclo macroeconômico pode ser explicada (ainda que parcialmente) por fatores microeconômicos, particularmente pelo alto grau de oligopolização da economia ${ }^{20}$. Em terceiro lugar, destaca-se a proposição de que a emissão de moeda decorre de uma reação passiva da autoridade monetária diante do aumento dos preços, a fim de se evitar uma crise de liquidez. Trata-se de um segundo

\footnotetext{
${ }^{20}$ Modenesi et al. (2012) chamam a atenção para a relevância de fatores microeconômicos — regras de formação de preço, estruturas de mercado e padrões de concorrência — no mecanismo de transmissão da política monetária: "É razoável considerar que, em geral, setores oligopolizados (mais precisamente, com maior poder de mercado) tendem a ser mais inflacionários por pelo menos duas razões: i) têm maior capacidade de repassar para os preços aumentos de custo; e ii) podem ser relativamente imunes aos efeitos contracionistas da PM [política monetária], visto que não necessariamente concorrem via preço” (p. 214). Modenesi e Modenesi (2012) ressaltam: “[...] a importância dos oligopólios e/ou das altas margens de lucro praticadas no país enquanto fator explicativo para a persistência da inflação em níveis elevados" (p. 406).
} 
rompimento de Rangel com teoria monetarista: a inversão da relação de causalidade entre moeda e preços prevista pela TQM. Essa visão de Rangel permitiu a Bresser e Nakano identificarem o papel sancionador do Estado no processo inflacionário;

2. A explicitação e formalização por Bresser e Nakano (1984a; 1984b) de uma relação funcional positiva entre recessão e inflação. Bresser e Nakano também consideram a inflação como resultante do desenvolvimento da fase do capitalismo oligopolista no país. Ao identificarem um comportamento mais agressivo (i.e., aumentando as margens de lucro) dos oligopólios em momentos de recessão, eles contribuíram para a definição de uma maneira mais explícita e formalizada da curva por parte de Rangel (1985b);

3. Contemporaneamente, Bresser e Rego (2013), destacaram o papel das crises do balanço de pagamentos, em momentos de recessão, na aceleração inflacionária. Ao adicionar o problema da restrição externa - fenômeno recorrente em economias periféricas, enfatizado pela abordagem estruturalista -, Bresser e Rego incorporaram um importante elemento de certa forma negligenciado por Rangel.

Em suma, ousadia, independência intelectual e originalidade são os traços mais distintivos da obra de Rangel, que desenvolve uma análise inteiramente peculiar da inflação. A sua curva revolucionária foi uma de suas mais relevantes contribuições. Meio século após a publicação de $A$ inflação brasileira, em que os fundamentos da curva de Rangel estão postos, ela continua sendo debatida e aprofundada. Chamamos os jovens economistas a se debruçarem sobre a contribuição de Rangel a fim de dar continuidade a esse processo.

\section{REFERÊNCIAS BIBLIOGRÁFICAS}

BIELSCHOWSKY, R. (1988) Pensamento Econômico Brasileiro: O Ciclo Ideológico do Desenvolvimento. Rio de Janeiro: IPEA/INPES.

BRESSER-PEREIRA, L.C. (1981) "A inflação no capitalismo de Estado (e a experiência brasileira recente)". Revista de Economia Política, 1(2): 3-41.

BRESSER-PEREIRA, L.C. (2010) “A descoberta da inflação inercial”. Revista de Economia Contemporânea, 14(1): 167-192.

BRESSER-PEREIRA, L.C.; NAKANO, Y. (1984a) "Fatores aceleradores, mantenedores e sancionadores da inflação”. Revista de Economia Política, 4(1): 5-21.

BRESSER-PEREIRA, L.C.; NAKANO, Y. (1984b) "Política administrativa de controle da inflação". Revista de Economia Política, 4(3): 105-125.

BRESSER-PEREIRA, L.C.; NAKANO, Y. (1986) “Inflação inercial e curva de Phillips”. Revista de Economia Política, 6(2): 69-76.

BRESSER-PEREIRA, L.C.; REGO, J.M. (1993) “Um mestre da economia brasileira: Ignácio Rangel”. Revista de Economia Política, 13(2): 98-119.

BRESSER-PEREIRA, L.C.; REGO, J.M. (2013) "Um mestre da economia brasileira: Ignácio Rangel revisitado”. Trabalho para o centenário do nascimento de Ignácio Rangel de dezembro de 2013 a ser publicado pelo CORECON-MA e pela UFMA. 
CARVALHO, F.J.C. (1993). “Sobre a endogenia da oferta monetária: réplica ao professor Nogueira da Costa”. Revista de Economia Política, 13(3): 114-121.

CARVALHO, F.J.C. (2013). “Keynes and the endogeneity of money”. Seminários de Pesquisa, IE/UFRJ, 11 jun. 2013.

CASTRO, M.H. (2012) “Nosso mestre Ignácio Rangel”. In: BENJAMIN, C. (Org.). Ignácio Rangel — Obras Reunidas 2. 3. ed. Rio de Janeiro: Contraponto.

COSTA, F.N. da (1993) “(Im)propriedades da moeda”. Revista de Economia Política, 13(2): 61-75.

DAVIDSON, P. (1977) “A keynesian view of Friedman's theoretical framework for monetary analysis”. In: GORDON, R.J. (Ed.). Milton Friedman's Monetary Framework: A Debate with his Critics. Chicago: Chicago University Press.

FRIEDMAN, M. (1956) “The quantity theory of money - a restatement”. In: FRIEDMAN, M. (Ed.). Studies in the quantity theory of money. Chicago: Chicago University Press.

FRIEDMAN, M. (1968) "The role of monetary policy”. The American Economic Review, 58(1): 1-17.

FRIEDMAN, M. (1989) “Quantity theory of money”. In: EATWELL, J.; MILGATE, M.; NEWMAN, P. (Eds.). The New Palgrave: Money. Londres: Norton.

FULLARTON, J. (1845 [1969]) On the Regulation of Currencies. Nova York: Kelley.

FURTADO, C. (1959 [1986]) Formação Econômica do Brasil. São Paulo: Ed. Nacional.

KALDOR, N. (1982) The Scourge of Monetarism. Oxford: Oxford University Press.

MILL, J.S. (1848 [1983]) Princípios de Economia Política. São Paulo: Abril Cultural.

MODENESI, A.M.; PIRES-ALVES, C.C.; MARTINS, N.M. (2012) “Mecanismo de transmissão de política monetária: a importância dos fatores microeconômicos”. Oikos, 11(2): 203-216.

MODENESI, A.M.; MODENESI, R.L. (2012) “Quinze anos de rigidez monetária no Brasil pós-Plano Real: uma agenda de pesquisa”. Revista de Economia Política, 32(3): 389-411.

MOORE, B. (1988) Horizontalists and Verticalists: The Macroeconomics of Credit Money. Cambridge: Cambridge University Press.

NAKANO, Y. (1982 [1986]) “Recessão e Inflação”. In: BRESSER-PEREIRA, L. C.; NAKANO, Y. Inflação e Recessão. 2. ed. São Paulo: Brasiliense. Publicado originalmente na Revista de Economia Política, 2(2).

NOYOLA, J. (1956) "El desarrollo econômico y la inflación en México y otros países latinoamericanos". Investigación Económica, 16(4).

NOYOLA, J. (1957 [2000]) "Inflação e desenvolvimento econômico no Chile e no México". In: BIELSCHOWSKY, R. Cinquenta Anos de Pensamento na CEPAL. Vol.1. Rio de Janeiro: Record.

PHILLIPS, A.W. (1958) "The relation between unemployment and the rate of change of money wage rates in the United Kingdom, 1861-1957”. Economica, v.25, nov., p. 283-299.

PINTO, S.C.A. (1961) “El análisis de la inflación, estructuralistas y monetaristas: un recuento”. Revista Económica Latinoamericana, 4.

RANGEL, I. (1957) “A Dualidade Básica da Economia Brasileira”. Rio de Janeiro: Instituto Superior de Estudos Brasileiros.

RANGEL, I. (1962) "A dinâmica da dualidade brasileira". Revista Brasileira de Ciências Sociais, UFMG, 2(2): 215-235.

RANGEL, I. (1963 [1978]) A Inflação Brasileira. São Paulo: Brasiliense.

RANGEL, I. (1981) "História da dualidade brasileira”. Revista de Economia Política, 1(4): 5-34.

RANGEL, I. (1983a) “A distribuição da renda”. Folha de São Paulo. São Paulo, 3 ago. 1983. Disponível em: http://www.interpretesdobrasil.org/sitePage/79.av. Acesso em: 6 jun. 2014.

RANGEL, I. (1983b) “A inflação na linha direta da superação da crise atual”. Folha de São Paulo. São Paulo, 16 ago. 1983. Disponível em: http://www.interpretesdobrasil.org/sitePage/79.av. Acesso em: 6 jun. 2014.

RANGEL, I. (1985a [2012]) “A presente problemática da economia brasileira”. In: BENJAMIN, C. (Org.). Ignácio Rangel — Obras Reunidas 2. 3. ed. Rio de Janeiro: Contraponto. Publicado originalmente no Boletim do Instituto dos Economistas do Rio de Janeiro, n. 31, mar./ago. 1985.

RANGEL, I. (1985b) “Recessão, inflação e dívida interna”. Revista de Economia Política, 5(3): 5-25. 
RANGEL, I. (1985c) “Ainda sobre a inflação inercial”. Folha de São Paulo. São Paulo, 5 nov. 1985. Disponível em: http://www.interpretesdobrasil.org/sitePage/79.av. Acesso em: 6 jun. 2014.

RANGEL, I. (1986) “A inflação e os juros”. Folha de São Paulo. São Paulo, 1986. Disponível em: http://www.interpretesdobrasil.org/sitePage/79.av. Acesso em: 6 jun. 2014.

RANGEL, I. (1987a) A Economia Brasileira Contemporânea. São Paulo: Bienal.

RANGEL, I. (1987b) “A componente inercial”. Folha de São Paulo. São Paulo, 21 jan. 1987. Disponível em: http://www.interpretesdobrasil.org/sitePage/79.av. Acesso em: 6 jun. 2014.

RANGEL, I. (1988a) “Ainda a inflação”. Folha de São Paulo. São Paulo, 18 fev. 1988. Disponível em: http://www.interpretesdobrasil.org/sitePage/79.av. Acesso em: 6 jun. 2014.

RANGEL, I. (1988b) “A inflação e o Cruzado". Folha de São Paulo. São Paulo, 31 jul. 1988. Disponível em: http://www.interpretesdobrasil.org/sitePage/79.av. Acesso em: 6 jun. 2014.

RANGEL, I. (1988c) “Ainda sobre a inércia acelerada”. Folha de São Paulo. São Paulo, 17 out. 1988. Disponível em: http://www.interpretesdobrasil.org/sitePage/79.av. Acesso em: 6 jun. 2014.

RANGEL, I. (1988d) “Inflação e distribuição de renda”. Folha de São Paulo. São Paulo, 8 nov. 1988. Disponível em: http://www.interpretesdobrasil.org/sitePage/79.av. Acesso em: 6 jun. 2014.

RANGEL, I. (1989) “A indexação”. Folha de São Paulo. São Paulo, 7 jan. 1989. Disponível em: http:// www.interpretesdobrasil.org/sitePage/79.av. Acesso em: 6 jun. 2014.

RANGEL, I. (1990) “O papel da inflação”. Folha de São Paulo. São Paulo. Disponível em: http://www. interpretesdobrasil.org/sitePage/79.av. Acesso em: 6 jun. 2014.

SAMUELSON, P. A. (1955) Economics. Nova York: McGraw-Hill.

SAMUELSON, P.A.; SOLOW, M. (1960) "Analytical aspects of anti-inflation policy". American Economic Review, maio, p. 177-194.

SEERS, D. (1962) "A theory of inflation and growth in underdeveloped economies based on the experience of Latin America”. Oxford Economic Papers, 14: 173-195.

SERRANO, F. (1986) “Inflação inercial e desindexação neutra”. In: REGO, J.M. (Org.). Inflação Inercial, Teorias sobre Inflação e o Plano Cruzado. 2. ed. Rio de Janeiro: Paz e Terra, cap.4.

SERRANO, F. (2010) "O conflito distributivo e a teoria da inflação inercial”. Revista de Economia Contemporânea, 14(2): 395-421.

SUNKEL, O. (1958) "La inflación chilena: un enfoque heterodoxo". El Trimestre Económico, 25(4).

THORNTON, H. (1802 [1965]) An Enquiry into the Nature and Effects of the Paper Credit of Great Britain. Nova York: Kelley.

TOOKE, T. (1856 [1972]) A History of Prices and of the State of the Circulation from 1792 to 1856. Nova York: Johnson Reprint Corporation.

TORRES, A. (1914 [1982]) O Problema Nacional Brasileiro. Brasília: Editora da Universidade de Brasília.

WEINTRAUB, S. (1978) Keynes, Keynesians and Monetarists. Philadelphia: University of Pennsylvania Press.

WICKSELL, K. (1898 [1965]) Interest and Prices: a study of the causes regulating the value of Money. Nova York: Kelley. 